\title{
Surfactant function affected by airway inflammation and cooling: possible impact on exercise-induced asthma
}

\author{
G. Enhorning ${ }^{+}$, J. Hohlfeld*, N. Krug*, G. Lema ${ }^{+}$, R.C. Welliver ${ }^{\#}$
}

\begin{abstract}
Surfactant function affected by airway inflammation and cooling: possible impact on exercise-induced asthma. G. Enhorning, J. Hohlfeld, N. Krug, G. Lema, R.C. Welliver. (C)ERS Journals Ltd 2000.

ABSTRACT: Pulmonary surfactant maintains patency of narrow conducting airways. An inflammation, with a leakage of plasma proteins into the airway lumen, causes surfactant to lose some of this ability. Will a lowering of temperature aggravate the deteriorating effect of an inflammation?

Calf lung surfactant extract (CLSE) with proteins added was studied with a capillary surfactometer (CS) at temperatures of $25-42^{\circ} \mathrm{C}$. BALB/c mice were infected with respiratory syncytial virus (RSV). Six days later the lungs were lavaged and the surfactant in the lavage fluid was studied with the CS at temperatures of $25-42{ }^{\circ} \mathrm{C}$. Lavage fluid from allergen challenged asthmatics was examined for its content of surfactant inhibitors at reduced temperatures.

It was shown that CLSE with proteins gradually lost its ability to maintain patency as the temperature was lowered. Lavage fluid from the RSV infected mice showed a similar dysfunction at low temperatures. Lavage fluid from the airways of human asthmatics, when challenged with antigen but not with saline, contained agents inhibiting surface activity, particularly at reduced temperatures.

Airway inflammation causes surfactant to lose its ability to maintain patency, particularly as the temperature is reduced. That might be a reason for the increased airway resistance observed in asthma patients hyperventilating in cold weather. Eur Respir J 2000; 15: 532-538.
\end{abstract}

\begin{abstract}
Depts of ${ }^{+}$Gynecology/Obstetrics and ${ }^{\#}$ Pediatrics, State University of New York at Buffalo, NY, USA. *Dept of Respiratory Medicine, Hannover Medical School, Hannover, Germany.

Correspondence: G. Enhorning, Perinatal Center, Children's Hospital, 219 Bryant Street, Buffalo, NY 14222, USA. Fax: 1 7168883833
\end{abstract}

Keywords: Airway cooling airway resistance

asthma

capillary surfactometer

pulmonary surfactant dysfunction

Received: April 211999

Accepted after revision November 291999

This research was supported by the National Heart, Lung, and Blood Institute Grant No. HL-49971 and by a grant from the Deutsche Forschungsgemeinschaft No. $\mathrm{Kr} 1405 / 2-1$
Pulmonary surfactant stabilizes alveoli and maintains patency of conducting airways. It has been demonstrated that the inflammation caused by exposure to ozone $[1,2]$ or by an infection with respiratory syncytial virus (RSV) $[3,4]$ inactivates the surfactant system and leads to disturbed breathing. More recently it has been shown $[5,6]$ that the inflammation developing in patients with mild asthma who have been challenged with an allergen causes surfactant to lose its ability to maintain patency. Most likely the inability was due to a leakage of plasma proteins into the airway lumen since it was noted that protein concentration in the lavage fluid was increased. Also, when the surfactant in the lavage fluid was separated by centrifugation it was no longer inhibited whereas the supernatant contained water soluble inhibiting agents.

Evidence has accumulated indicating that a surfactant dysfunction in terminal conducting airways will lead to formation of liquid columns that may block the airways during part of the respiratory cycle [1-9]. Such liquid columns will form more readily if the amount of airway liquid is increased due to hypersecretion or if the inflammation has caused oedema in the airway wall, whereby the lumen has become more narrow [8]. As a consequence of airway blockage in many small airways it may be anticipated that airway resistance will increase and that possibly hyperinflation will ensue. Those features of asthma may be caused by ozone exposure [10] or by RSV infection [11], conditions that both trigger an inflammatory reaction. Since it has now been established that in mild asthmatics an allergen challenge inducing an inflammatory reaction will provoke a surfactant dysfunction $[5$, $6]$, it appears very likely that the increase in airway resistance characterizing an asthma attack is partly due to a surfactant dysfunction. Since an asthma attack will often be triggered in asthmatics exercising and therefore hyperventilating in cold weather, it appears logical to evaluate surfactant's ability to maintain patency at temperatures below those of the body.

This article describes how a change in ambient temperature will affect the function of pulmonary surfactant that has been modified by an inflammation. The inflammatory reaction was simulated or obtained in three ways: 1) by adding plasma proteins to a well-functioning surfactant preparation; 2) by infecting BALB/c mice with RSV; and 3) by challenging mild asthmatics with an allergen.

\section{Material and methods}

A capillary surfactometer (CS; Calmia Medical Inc., Toronto, Ontario, Canada) was used for an evaluation of surfactant's ability to maintain airway patency. This instrument has been used for several studies and has been fully 
described [1-8]. Briefly, it has a glass capillary with a narrow section where the width (inside diameter (ID) $=0.3$ $\mathrm{mm}$ ) is similar to that of the human lung's terminal conducting airway [12]. In this narrow part of the capillary, a small volume $(0.5 \mu \mathrm{L})$ of the liquid to be evaluated is deposited. The liquid blocks the constricted lumen, but when pressure is raised at one end of the capillary, the liquid is pushed out of the narrow section whereby pressure is abruptly lowered as air gets through.

If the liquid studied contains pulmonary surfactant that will quickly form a surfactant film exerting high surface pressure, it will not return to the narrow section, and the continuous airflow through the capillary will meet no resistance. Consequently, pressure will remain at zero during a 2 min period of recording. If, on the other hand, surfactant function is inhibited so that film adsorption is deisyed or the exerted surface pressure is reduced, then the liquid extruded from the narrow section will return and again block the capillary lumen. The return may be delayed, or it may be immediate and in some cases so rapid that a pressure of zero will never be reached. The steady airflow, lasting for 2 min after the liquid was initially extruded, will then meet resistance and pressure will be raised repeatedly as the liquid returns to the narrow section. A minicomputer calculates the percentage of the 2-min study period that pressure remained at zero. If the dysfunction is pronounced, pressure zero is hardly ever recorded and the CS will print the result, the "Open in percentage", as zero or slightly above. When the surfactant is functioning optimally the print-out will show that the capillary was open $100 \%$.

\section{Temperature regulation}

The temperature of the water bath, in which the glass capillary of the CS is immersed, is regulated with a thermostat and is normally kept at $37^{\circ} \mathrm{C}$, but for this study temperature was gradually raised $1{ }^{\circ} \mathrm{C}$ at a time from $25-$ $42^{\circ} \mathrm{C}$, or it was gradually lowered within that range. At each temperature level, three assays were carried out and the mean was the value used.

\section{Calf lung surfactant extract with plasma proteins}

Calf lung surfactant extract (CLSE) was the surfactant preparation used for this study. In composition and function it is similar to natural surfactant and it has been used for prevention and treatment of the respiratory distress syndrome (RDS) in newborn infants. CLSE was kindly donated by the manufacturer (ONY Inc., Amherst, NY, USA). It is supplied in $5 \mathrm{~mL}$ vials at a concentration of 35 $\mathrm{mg} \cdot \mathrm{mL}^{-1}$. When albumin or other plasma proteins were added, the CLSE was diluted with saline solution to 4 $\mathrm{mg} \cdot \mathrm{mL}^{-1}$ so that when it was mixed with an equal volume of the protein solution its final concentration became 2 $\mathrm{mg} \cdot \mathrm{mL}^{-1}$. Bovine albumin and fibrinogen were purchased from Sigma, St. Louis, MO, USA. Albumin was dissolved in saline solution and when mixed with the CLSE suspension its final concentrations became 5, 6, 7, 8, 9, and 10 $\mathrm{mg} \cdot \mathrm{mL}^{-1}$.

Fibrinogen, known to be a more active surfactant inhibitor $[13,14]$ was given a final concentration of 0.07 $\mathrm{mg} \cdot \mathrm{mL}^{-1}$ when studied at various temperatures with CLSE, $2 \mathrm{mg} \cdot \mathrm{mL}^{-1}$.

Various concentrations of calf lung surfactant extract studied with albumin

When CLSE had a concentration of $2 \mathrm{mg} \cdot \mathrm{mL}^{-1}$ it was inhibited by albumin, $10 \mathrm{mg} \cdot \mathrm{mL}^{-1}$, even at body temperature, and with cooling the inhibition became pronounced. To investigate whether the inhibition would be less serious when the surfactant concentration was raised, CLSE was studied at final concentrations of $2,3,4$, and $5 \mathrm{mg} \cdot \mathrm{mL}^{-1}$, all with the same albumin "contamination" of $10 \mathrm{mg} \cdot \mathrm{mL}^{-1}$. Temperature was gradually raised from $25-42^{\circ} \mathrm{C}$.

\section{Bronchoalveolar lavage fluid from respiratory syncytial virus infected mice}

$\mathrm{BALB} / \mathrm{c}$ mice, 12-15 weeks old, of male sex and weighing 22-25 g were used for this part of the study, which was approved by the Institutional Animal Care and Use Committee of the State University of New York at Buffalo, NY, USA. Eight of the mice served as healthy control animals whereas eight were inoculated four times with 50 $\mu \mathrm{L}$ of RSV stock solution, resulting in a high dose, $1 \times$ $10^{6}-2 \times 10^{7}$ plaque forming units (pfu). Six days after inoculation, when according to previous studies [3, 4] breathing is most affected, the animals received a lethal i.p. dose of pentobarbital $\left(100 \mathrm{mg} \cdot \mathrm{kg}\right.$ body weight $\left.{ }^{-1}\right)$. The lungs were lavaged with saline solution, the volume of which in millilitres was $2 \%$ of the body weight in grams. Introduction as well as withdrawal of the liquid was regulated with pressure according to a technique previously described [3]. A positive pressure of $30 \mathrm{~cm}$ of water was used for the fluid's introduction and a negative pressure of $20 \mathrm{~cm}$ of water for its withdrawal. Approximately 80 $90 \%$ of the fluid was retrieved with the first withdrawal, but the lavage procedure was repeated six times with the same fluid which lowered the final return to $\sim 65 \%$. On top of the lavage fluid, a layer of foam was formed. It was rich in surfactant and to incorporate it with the rest of the lavage fluid it was liquefied by repeatedly exposing the fluid to vacuum. To remove cells and cell debris the fluid was centrifuged at low speed $(1,000 \times g)$ for $5 \mathrm{~min}$. The supernatant was centrifuged at high speed $(40,000 \times g)$ and at $4{ }^{\circ} \mathrm{C}$ for $1 \mathrm{~h}$. A volume of supernatant which was $80 \%$ of the fluid used for the second centrifugation was removed, and the remaining $20 \%$, which contained the large aggregate surfactant, was stirred and was then ready for studies with the CS. The centrifugation procedure concentrated the bronchoalveolar lavage (BAL) fluid surfactant approximately five times.

\section{Bronchoalveolar lavage fluid from patients with mild asthma following a segmental challenge with allergen}

Patients with mild asthma $(\mathrm{n}=15)$ underwent bronchoscopy for endobronchial challenge of contralateral lung segments, with allergen and vehicle, respectively. The procedure did not affect the patients' breathing. Twenty-four hours later the allergen and sham challenged segments 
were lavaged. Control BAL fluids were obtained from healthy volunteers $(n=9)$. This clinical part of the study was carried out in Hannover, Germany, and was approved by the Ethics Committee of Hannover Medical School. Informed consent was obtained from each person in the study. BAL fluid was centrifuged $250 \times g$ for $10 \mathrm{~min}$ to remove cells and debris. The cell free fluid was then centrifuged at $40,000 \times g$ and $4^{\circ} \mathrm{C}$ for $1 \mathrm{~h}$ to obtain a pellet of surfactant. The supernatant we knew from a previous study [5] contained water soluble surfactant inhibitors when the fluid originated from allergen challenged segments of asthmatics. To increase the inhibitor concentration, the supernatant was evaporated until its volume had been reduced to a fifth, and it was then used for a dilution of CLSE from 35 to $1 \mathrm{mg} \cdot \mathrm{mL}^{-1}$. The surface activity of the CLSE, diluted with the concentrated BAL fluid supernatant, was studied with the CS and was expressed as "Open in percentage". When CLSE underwent such a dilution with saline solution it maintained $100 \%$ patency. The BAL fluids from the allergen challenged lung segments were pooled and compared with the pooled fluids from the segments exposed to nothing but saline solution and with the pooled fluids from the healthy volunteers. The pooling was necessary to obtain an adequate quantity of the concentrated BAL fluid supernatant so that the mean of three determinations at each degree, from 25$42^{\circ} \mathrm{C}$, could be obtained.

\section{Statistical analysis}

The CS value of a sample at a specific temperature was the mean of three assays. The effect of temperature was expressed with linear regression. Diversity in means of treatment groups (healthy and infected mice) was tested with an unpaired Student t-test and, when the material was not normally distributed, with a Mann-Whitney U-test. A p-value of $<0.05$ was considered to indicate a significant difference.

\section{Results}

\section{CLSE with albumin and fibrinogen}

When the albumin concentrations were low, 5, 6 and 7 $\mathrm{mg} \cdot \mathrm{mL}^{-1}$ (fig. 1a), they had no conspicuous effect on CLSE, $2 \mathrm{mg} \cdot \mathrm{mL}^{-1}$, when studied at temperatures $>30^{\circ} \mathrm{C}$. However, as seen from figure $1 \mathrm{~b}$, the ability to preserve patency diminished when the protein concentration was 8,9 or $10 \mathrm{mg} \cdot \mathrm{mL}^{-1}$, and at the highest protein concentrations a compromising effect was noted at $37^{\circ} \mathrm{C}$ and even slightly above. With lowering of temperature the ability to preserve patency was drastically reduced. The inhibiting action of the two plasma proteins studied, albumin and fibrinogen, appeared to be similar and equally affected by a lowering of temperature (fig. 2). However, it should be noted that the concentration of albumin was 100 times greater than that of fibrinogen. Figure 3 shows that it was of no serious consequence if temperature was raised from $25-42^{\circ} \mathrm{C}$ or if it was gradually lowered within this range.
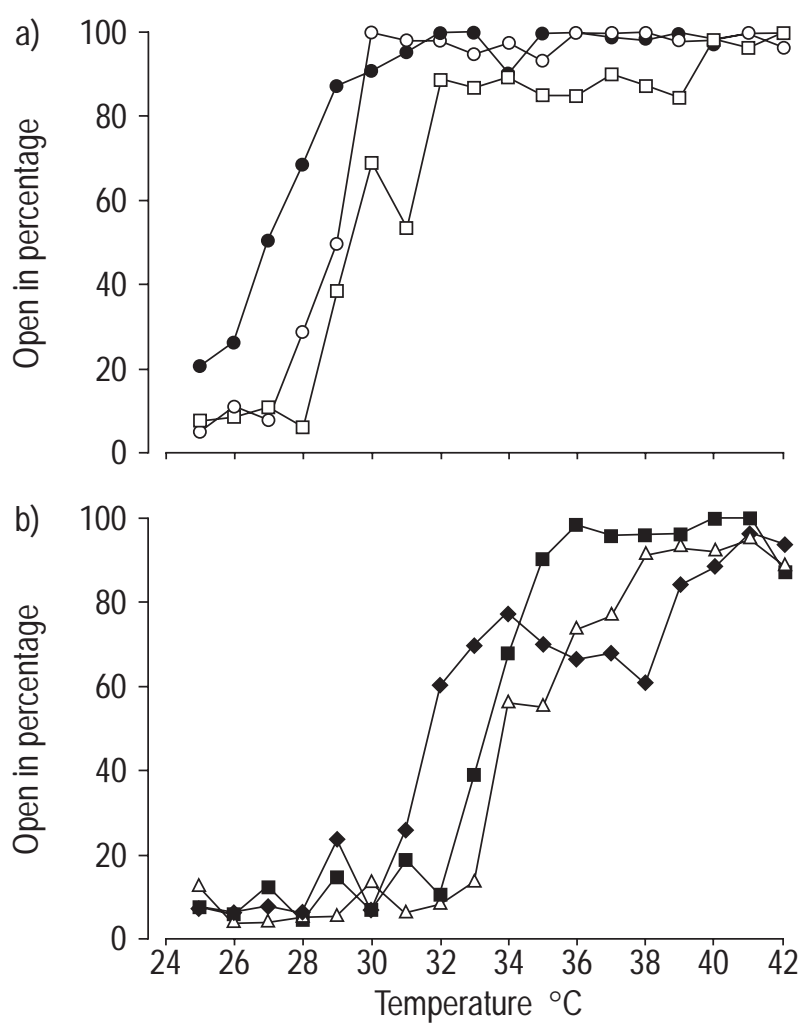

Fig. 1. - When calf lung surfactant extract concentration was $2 \mathrm{mg} \cdot \mathrm{mL}^{-1}$, a low albumin concentration was tolerated as long as temperature was $>30^{\circ} \mathrm{C}$ (a), but when albumin concentrations were high (b), there was less tolerance to a lowering of temperature. a) 0 : albumin $5 \mathrm{mg} \cdot \mathrm{mL}^{-1} ; \bigcirc$ : albumin $6 \mathrm{mg} \cdot \mathrm{mL}^{-1} ; \square: 7 \mathrm{mg} \cdot \mathrm{mL}^{-1}$. b) $\square:$ albumin $8 \mathrm{mg} \cdot \mathrm{mL}^{-1} ; \triangle$ : albumin $9 \mathrm{mg} \cdot \mathrm{mL}^{-1} ;$ : albumin $10 \mathrm{mg} \cdot \mathrm{mL}^{-1}$.

Increasing the calf lung surfactant extract concentration overcomes the albumin inhibition

As seen in figure $1 \mathrm{~b}$, an albumin concentration of 10 $\mathrm{mg} \cdot \mathrm{mL}^{-1}$ had a severely inhibiting effect when the CLSE concentration was $2 \mathrm{mg} \cdot \mathrm{mL}^{-1}$, but the inhibition exerted by this albumin content was less noticeable as the surfactant concentration was raised (fig. 4).

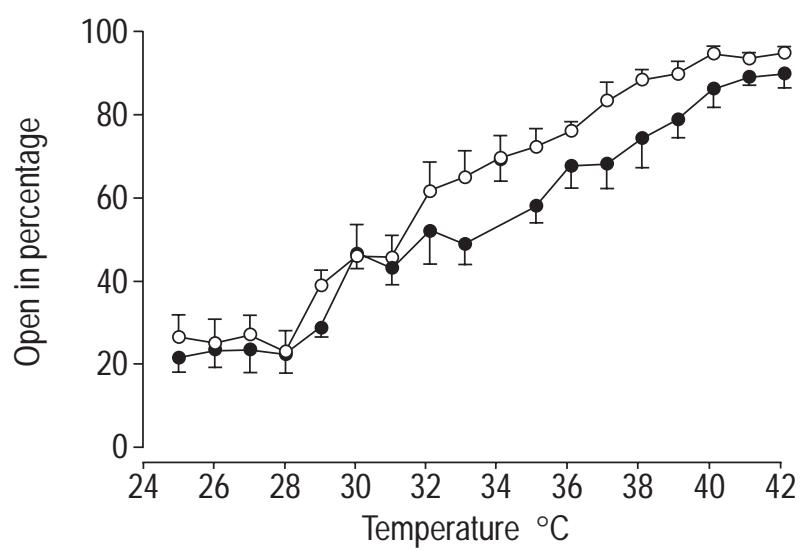

Fig. 2. - Calf lung surfactant extract (CLSE) inhibited by plasma proteins. Although the concentration of albumin was a hundred times higher than that of fibrinogen, the inhibition appeared to be similar. The values were obtained by studying five different mixtures of CLSE, $2 \mathrm{mg} \cdot \mathrm{mL}^{-1}$, with respective protein. The tracings were obtained by gradually raising the temperature. $\bigcirc$ : albumin $7 \mathrm{mg} \cdot \mathrm{mL}^{-1}$; $:$ fibrinogen $0.07 \mathrm{mg} \cdot \mathrm{mL}^{-1}$. Values are mean \pm SEM. 


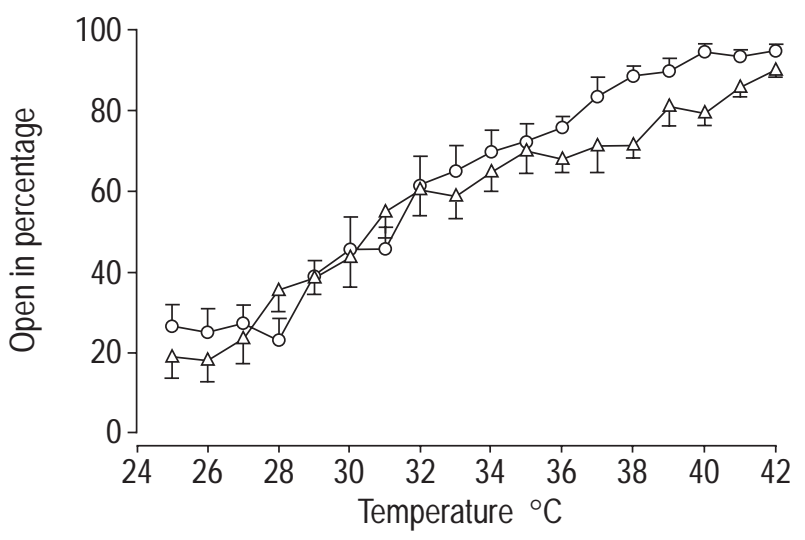

Fig. 3. - The albumin tracing of figure 2 , obtained by gradually raising the temperature, is compared with the tracing obtained when the temperature was gradually lowered. The direction of temperature change appeared to be of minimal consequence. $\bigcirc$ : albumin $7 \mathrm{mg} \cdot \mathrm{mL}^{-1}$, increasing temperature; $\triangle$ : albumin $7 \mathrm{mg} \cdot \mathrm{mL}^{-1}$, decreasing temperature.

\section{Bronchoalveolar lavage fluid from mice}

The BAL fluid from healthy mice maintained patency quite well at $37^{\circ} \mathrm{C}$ but slowly lost some of that ability as temperature was lowered (fig. 5). However, the BAL fluid from the infected mice had a reduced capability to maintain patency at body temperature, and as temperature was reduced, the value of "Open in percentage" diminished even further. When the median value at $37^{\circ} \mathrm{C}$ obtained for the eight healthy mice $(72 \%)$ was compared with the median value for the eight mice infected with RSV (27\%), the difference was highly significant, $\mathrm{p}<0.0001$, and with reduction in temperature the difference became even greater.

Supernatant of bronchoalveolar lavage fluid from asthmatics inhibits calf lung surfactant extract

When the concentrated BAL fluid supernatant was used to dilute CLSE to $1 \mathrm{mg} \cdot \mathrm{mL}^{-1}$, it had only a minor inhibiting

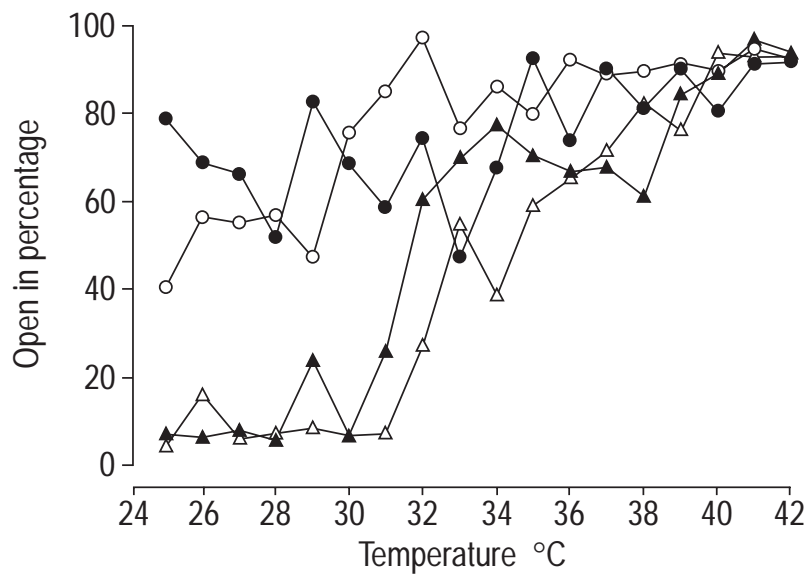

Fig. 4. - When albumin contamination was high, $10 \mathrm{mg} \cdot \mathrm{mL}^{-1}$, patency was not optimal, but improved by increasing the surfactant concentration. $\bigcirc$ : calf lung surfactant extract (CLSE) $5 \mathrm{mg} \cdot \mathrm{mL}^{-1} ; \bigcirc$ : CLSE 4 $\mathrm{mg} \cdot \mathrm{mL}^{-1} ; \triangle \mathrm{CLSE} 3 \mathrm{mg} \cdot \mathrm{mL}^{-1} ; \boldsymbol{\Delta}: 2 \mathrm{mg} \cdot \mathrm{mL}^{-1}$.

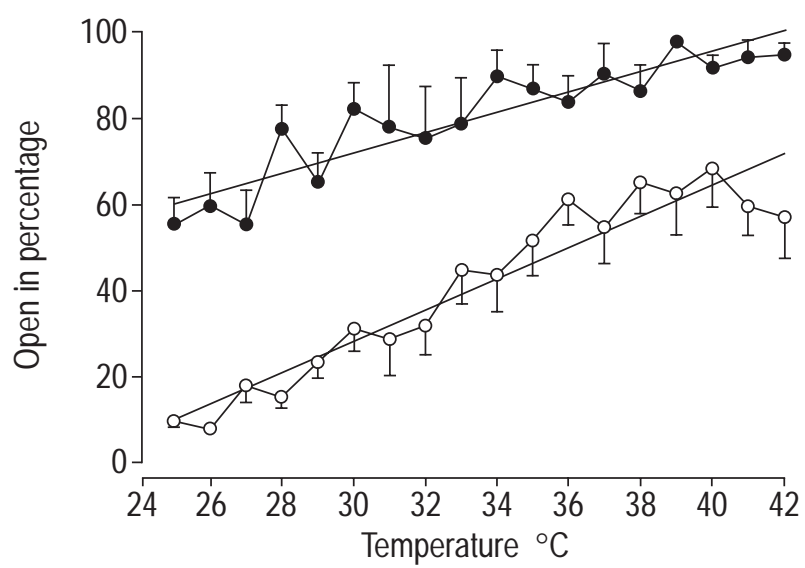

Fig. 5. - Bronchoalveolar lavage (BAL) fluid from healthy BALB/c mice (1) maintained patency well at body temperature but lost some of that ability as temperature was lowered. When the BAL fluid came from respiratory syncytial virus (RSV) infected mice $(O)$ the ability to maintain patency was reduced at body temperature and deteriorated seriously as temperature was lowered. $\mathrm{n}=8$ in both groups. For healthy mice regression coefficient $(\mathrm{R})=0.905, \mathrm{p}<0.0001$, and for RSV infected mice $\mathrm{R}=0.953, \mathrm{p}<0.0001$. Values are expressed as mean \pm SEM. Lines of linear regression are shown.

effect when it originated from healthy volunteers or from the lung segments of asthmatics, challenged with nothing but saline solution (fig. 6). However, when the supernatant originated from lung segments of asthmatics, challenged with allergen, the surfactant was clearly inhibited. Furthermore, as temperature was lowered, the inhibition was augmented (regression coefficient $(\mathrm{R})=0.754, \mathrm{p}=0.0005)$. The median values for "Open in percentage" when the BAL fluid supernatant originated from healthy volunteers, saline challenged, and allergen challenged asthmatics were $97.3 \%, 95.9 \%$, and $35.0 \%$, respectively.

\section{Discussion}

Patency was considered to exist when liquid columns were not blocking the capillary of the CS. When the capillary remained unblocked during the entire 2-min study period patency was defined as being $100 \%$. That degree of patency probably required an extremely fast phospholipid adsorption. As the liquid column is extruded from the narrow section of the glass capillary, so that air can pass, a surfactant film exerting high surface pressure must immediately form at the air-liquid interface, otherwise the liquid will again accumulate in the narrow section. The surfactant apoproteins surfactant protein (SP)-B and SP-C, present in CLSE, are known to serve this important role of increasing the rate of adsorption [15-18]. However, when water soluble proteins are present at a critical concentration they have been shown to inhibit the formation of a pulmonary surfactant film $[13,14,19]$. They probably reach the air-liquid interface before the phospholipids do, and thereby prevent the formation of a well functioning monolayer.

When albumin had been added but was at low concentration, as it might be when the asthma inflammation is mild, the patency capacity was not seriously affected at normal body temperature, but cooling to $<30^{\circ} \mathrm{C}$ resulted in a conspicuous deterioration of the patency ability (fig. 1a). 


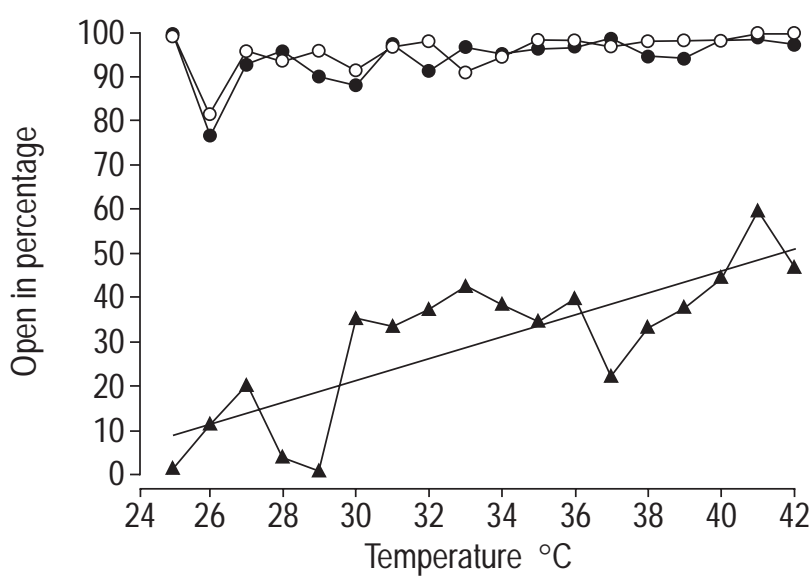

Fig. 6. - Bronchoalveolar lavage (BAL) fluids from healthy human volunteers $(O)$ or from lung segments of asthmatics, challenged with nothing but saline solution $(\mathbf{O})$, had a low concentration of inhibitors so that the ability of calf lung surfactant extract (CLSE) to maintain patency was not seriously interfered with, not even when temperature was lowered to $25^{\circ} \mathrm{C}$. However, when the $\mathrm{BAL}$ fluid originated from asthmatic patients, challenged with antigen, the fluid contained inhibitors that prevented CLSE from maintaining patency, particularly as temperature was lowered $(\boldsymbol{\Delta})$. Regression coefficient $=0.754, p=0.0005$. Line of linear regression is shown.

At higher albumin concentrations, 9 and $10 \mathrm{mg} \cdot \mathrm{mL}^{-1}$, surfactant inhibition was noted at a temperature that was equal to that of the body and it became very noticeable with cooling (fig. 1b). This suggests that the water soluble and therefore evenly distributed protein molecules were more capable of reaching the air-liquid interface than were the surfactant phospholipids. In the alveoli the surfactant molecules would have to be drafted from myelin figures or from bilayers in lamellar bodies, a procedure that probably in relation to protein adsorption would require more time. With a high albumin concentration, 10 $\mathrm{mg} \cdot \mathrm{mL}^{-1}$, which might simulate a severe inflammation, such as the one that is likely to develop during an acute asthma attack, the surface activity was lowered, even at normal body temperature.

At a surfactant concentration of $2 \mathrm{mg} \cdot \mathrm{mL}^{-1}$, an albumin contamination of $10 \mathrm{mg} \cdot \mathrm{mL}^{-1}$ resulted in severe inhibition. However, by increasing the surfactant concentration, this inhibition was counteracted, which suggests that by supplying more surfactant, inhibition caused by albumin, an RSV infection, or an asthma attack, might be oppressed. Patients who are prone to develop exercise-induced asthma (EIA) are less likely to contract serious problems if they prophylactically use $\beta$-adrenergic agonists, that function not only by relaxing smooth muscles but also by causing a release of surfactant from type II cells [20-23].

While the plasma proteins albumin and fibrinogen inhibited CLSE according to a similar pattern (fig. 2), it should be noted that the concentration of albumin was a hundred times greater than that of the fibrinogen. This demonstrates how the ability to inhibit surfactant can vary from one protein to another and, consequently, the total protein content might not be in proportion to the degree of inhibition.

The critical temperature at which surfactant was found to lose its ability to preserve airway patency also showed variations. When even a very low concentration of fibrinogen was contaminating CLSE, a deteriorating effect was observed as soon as temperature was below $37^{\circ} \mathrm{C}$. At $<30^{\circ} \mathrm{C}$ the plasma proteins tested, albumin and fibrinogen, were seriously affecting the patency ability. The question is, though, will temperature ever be lowered to that degree in narrow conducting airways, even when the lungs are hyperventilated and the ambient air is frigid?

MCFADDEN and coworkers [24-26] have carefully studied how the temperature of the airway is affected by that of the ambient air. The thermistors used were attached to a catheter with an outside diameter (OD) of $1.4 \mathrm{~mm}$ [24]. With that system they found that when a person is hyperventilating in frigid air, temperature in the lower trachea averages $23.5^{\circ} \mathrm{C}$. As expected, they found that in more peripheral airways temperature was not lowered as much. Nevertheless, a temperature of $27^{\circ} \mathrm{C}$ could be measured deep in the right lower lobe. In the discussion they pointed out that as the catheter entered a narrowing airway, it occupied more and more of the airway lumen and thus reduced the airflow. For that reason they felt that the airway cooling would most likely have been more extensive had the catheter not been there. In later publications the catheter used was more narrow (OD $0.9 \mathrm{~mm}$ ) which made it possible to study airways "less than $1.0 \mathrm{~mm}$ in diameter" [25]. The width of the catheter was evidently very close to that of the airway and the authors' suggestion that the catheter might have dampened the airflow did indeed appear appropriate. The current authors therefore suspect that airway cooling during hyperventilation may lead to temperatures lower than those measured.

The lowering of airway temperature is likely to be maximal as long as the strenuous exercise is maintained, but during that period airway resistance is usually less than it was before the exercise was initiated [26-29]. It was not until 5-10 min after the exercise was over and the patient was no longer hyperventilating that the airway resistance was conspicuously increased and remained greater than normal for $\sim 1 \mathrm{~h}$. It appears unlikely that the increased airway resistance that follows a period of exercise could be caused by a surfactant dysfunction developing because temperature was lowered. This would not appear to be

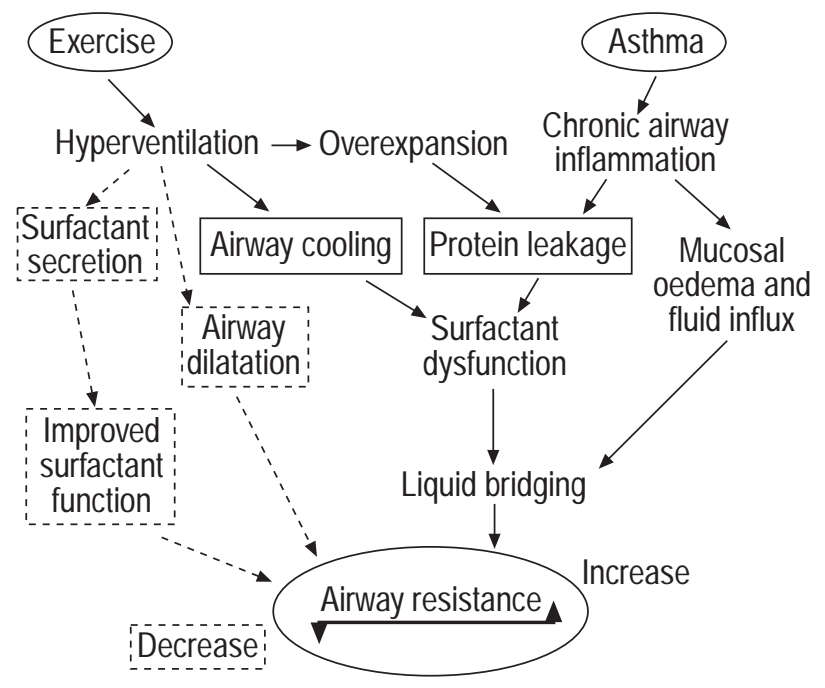

Fig. 7. - The possible impact of surfactant function on exercise-induced asthma. Mechanisms that cause airway obstruction are shown in black and mechanisms that alleviate airway obstruction are shown with dashed lines. 
plausible since symptoms do not develop until temperature has returned to normal. Nevertheless, what follows is a hypothesis that explains how the surfactant function of a person with asthma might be adversely affected by a period of exercise, particularly if the surrounding air is cold. Some of the symptoms of EIA might be explained by the surfactant dysfunction that develops (fig. 7).

If temperature in peripheral airways is reduced, a surfactant, affected by an inflammation caused by an RSV infection or asthma (figs. 5 and 6), will have a reduced capability of maintaining airway patency. However, as long as hyperventilation persists and thoracic gas volume is increased, peripheral airways are kept dilated so that airway resistance is reduced. The widening of the airway makes it less likely that a surfactant dysfunction will result in the formation of blocking liquid columns [8]; another reason for airway resistance to be reduced.

Though breathing at rest is hardly affected in a mild case of asthma, a certain number of conducting airways are likely to be blocked by liquid bridging over the airway lumen. As hyperventilation develops, the blocked airways may open up, but they might then be subjected to cooling by which the surfactant loses even more of its ability to maintain patency, and the loss is likely to be related to the degree of airway inflammation and the degree of cooling.

To keep the airways open in spite of their tendency to close as airway temperature is lowered, intrathoracic pressure must be reduced even further. Overexpansion of the lungs with a widening of conducting airways causes a reduced airway resistance, but it also results in an increased leakage of plasma proteins, further hampering the surfactant function. If the hyperventilation persists so that the lungs are kept overexpanded, the narrow airways remain open, thereby augmenting airflow in spite of the surfactant dysfunction that has developed. This concept agrees with the clinical observation that during the initial stage of exercising, airflow resistance diminishes as the lungs become hyperinflated.

Shortly after the exercise-induced hyperventilation has ended, values of forced expiratory volume in one second diminish, indicating that airway resistance has been augmented, and within $10 \mathrm{~min}$ it reaches a peak, from which it gradually diminishes. As the hyperventilation subsides, a large number of conducting airways are likely to be closing during expiration. They become blocked by liquid columns forming as a result of the surfactant dysfunction that has been augmented. There will be an increased tendency for liquid columns to form as the airways are narrowing [8]. A diminishing width of the airways may be caused by hyperaemia and oedema developing in the airway wall. The blocking of airways due to surfactant dysfunction may be the reason for residual volume to increase $43 \%$ in patients with asthma just after they have exercised [26].

There has been shown to be a leakage of plasma proteins into the airways of healthy human beings exposed to exercise levels, considered to be light, moderate, or heavy [30]. It would be of great interest to examine the BAL fluid of individuals who suffer from EIA and thereby put the current authors' hypothesis to the test. If BAL was carried out before and after a period of strenuous exercise it might be possible to show that after the exercise the protein concentration was higher and the surfactant in the BAL fluid had a reduced ability to maintain patency, particularly at temperatures below those of the body.
Animal studies have demonstrated that hyperventilation will lead not only to a leakage of proteins, but also to a release into the alveolar space of pulmonary surfactant [31]. Initially, the surfactant inhibiting effect of the invading proteins will be dominant, but as the concentration of surfactant is increased it is likely that it will regain its ability to adsorb quickly, and the monolayer that forms at the air-liquid interface will then exert a high surface pressure. This might be the reason for the recovery that usually takes place within $1 \mathrm{~h}$ after exercise. The surfactant release might also explain the development of a refractory period, during which renewed exercise results in less of an increase in airway resistance.

In conclusion, this study has shown that surfactant's ability to maintain patency is lower when there is an influence of inflammatory inhibitors and when airway temperature is reduced. Among the inhibitors tested were two plasma proteins: albumin and fibrinogen, the latter being considerably more potent. Other inhibitors were those appearing in the bronchoalveolar lavage fluid of respiratory syncytial virus infected mice and those present in the bronchoalveolar lavage fluid of patients with mild asthma who had been challenged with allergen $24 \mathrm{~h}$ previously. It was noted that some of the inflammatory conditions reduced surfactant's ability to maintain patency even with a very slight reduction in temperature, and that when it was reduced to $30^{\circ} \mathrm{C}$ or less, the patency was seriously affected. The findings point to the possibility that pulmonary surfactant, dysfunctioning because of inflammation and cooling, might have an impact on exercise-induced asthma.

\section{References}

1. Currie WD, van Schaik SM, Vargas I, Enhorning G. Ozone affects breathing and pulmonary surfactant function in mice. Toxicology 1998; 125: 21-30.

2. Currie WD, van Schaik S, Vargas I, Enhorning G. Breathing and pulmonary surfactant function in mice 24 hours after ozone exposure. Eur Respir J 1998; 12: 288-293.

3. van Schaik SM, Vargas I, Welliver RC, Enhorning G. Surfactant dysfunction develops in BALB/c mice infected with respiratory syncytial virus. Ped Res 1997; 42: 169173.

4. van Schaik SM, Enhorning G, Vargas I, Welliver RC. Respiratory syncytial virus affects pulmonary function in BALB/c mice. J Infect Dis 1998; 177: 269-276.

5. Hohlfeld JM, Ahlf K, Enhorning G, et al. Dysfunction of pulmonary surfactant in asthmatics after segmental allergen challenge. Am J Respir Crit Care Med 1999; 159: 1803-1809.

6. Jarjour NN, Enhorning G. Antigen-induced airway inflammation in atopic subjects generates dysfunction of pulmonary surfactant. Am J Respir Crit Care Med 1999; 160: 336-341.

7. Liu M, Wang L, Li E, Enhorning G. Pulmonary surfactant will secure free airflow through a narrow tube. $J \mathrm{Appl}$ Physiol 1991; 71: 742-748.

8. Enhorning G, Holm BA. Disruption of pulmonary surfactant's ability to maintain openness of a narrow tube. $J$ Appl Physiol 1993; 74: 2922-2927.

9. Enhorning G, Yarussi A, Rao P, Vargas I. Increased airway resistance due to surfactant dysfunction can be alleviated with aerosol surfactant. Can J Physiol Pharmacol 1996; 74: 687-691. 
10. Peden DB, Boehlecke B, Horatman D, Devlin R. Prolonged acute exposure to $0.16 \mathrm{ppm}$ ozone induces eosinophilic airway inflammation in asthmatic subjects with allergies. J Allergy Clin Immunol 1997; 100: 802-808.

11. Bjarnason SN, Sigurbergsson F, Kjellman B, Bjorksten B. Asthma and immunoglobulin $\mathrm{E}$ antibodies after respiratory syncytial virus bronchiolitis: a prospective cohort study with matched controls. Pediatrics 1995; 95: 500505 .

12. Weibel ER. Morphometry of the human lung. Academic press Inc., New York, USA, 1963; p. 124.

13. Seeger WG, Stohr G, Wolf HRD, Neuhof H. Alteration of surfactant function due to protein leakage: special interaction with fibrin monomer. $J$ Appl Physiol 1985; 58: 326-338.

14. Fuchimukai T, Fujiwara T, Takahashi A, Enhorning G. Artificial pulmonary surfactant inhibited by plasma proteins. J Appl Physiol 1987; 62: 429-437.

15. Curstedt $\mathrm{T}$, Jörnvall $\mathrm{H}$, Robertson $\mathrm{B}$, Bergman $\mathrm{T}$, Berggren P. Two hydrophobic low-molecular mass protein fractions of pulmonary surfactant: characterization and biophysical activity. Eur J Biochem 1987; 168: 255262.

16. Kobayashi T, Nitta K, Takahashi R, Kurashima K, Robertson B, Suzuki Y. Activity of pulmonary surfactant after blocking the associated proteins SP-A and SP-B. $J$ Appl Physiol 1991; 71: 530-536.

17. Notter RH, Shapiro DL, Ohning B, Whitsett JA. Biophysical activity of synthetic phospholipids combined with purified lung surfactant 6000 dalton apoproteins. Chem Phys Lipids 1987; 44: 1-17.

18. Yu S-H, Possmayer F. Role of pulmonary surfactantassociated proteins in the surface-active property of phospholipid mixtures. Biochim Biophys Acta 1990; 1046: 233-241.

19. Holm BA, Notter RH, Finkelstein JN. Surface property changes from interactions of albumin with natural surfactant and extracted lung lipids. Chem Phys Lipids 1985; 38: $287-298$.
20. Wyszogrodski I, Taeusch HW Jr, Avery ME. Isoxsuprineinduced alterations of pulmonary pressure-volume relationships in premature rabbits. Am J Obstet Gynecol 1974; 119: 1107-1111.

21. Enhorning G, Chamberlain D, Contreras C, Burgoyne R, Robertson B. Isoxsuprine-induced release of pulmonary surfactant in the rabbit fetus. Am J Obstet Gynecol 1977; 129: 197-202.

22. Oyarzun MJ, Clements J. Control of lung surfactant by ventilation, adrenergic mediators, and prostaglandins in the rabbit. Am Rev Respir Dis 1978; 117: 879-891.

23. Dobbs JG, Mason RJ. Pulmonary alveolar type II cells isolated from rats: release of phosphatidylcholine in response to beta-adrenergic stimulation. $J$ Clin Invest 1979; 63: 378-387.

24. McFadden EF Jr, Pichurko BM, Bowman HF, et al. Thermal mapping of the airways in humans. J Appl Physiol 1985; 58: 564-570.

25. Gilbert IA, Fouke JM, McFadden ER Jr. The effect of repetitive exercise on airway temperatures. Am Rev Respir Dis 1990; 142: 826-831.

26. Strauss RH, McFadden ER Jr, Ingram RH Jr, Jaeger JJ. Enhancement of exercise-induced asthma by cold air. $N$ Engl J Med 1977; 297: 743-747.

27. Freed AN. Models and mechanisms of exercise-induced asthma. Eur Respir J 1995; 8: 1770-1785.

28. Hendrickson CD, Lynch JM, Gleeson K. Exercise induced asthma: a clinical perspective. Lung 1994; 172: 1-14.

29. O'Byrne PM. Exercise-induced bronchoconstriction: elucidating the roles of leucotrienes and prostaglandins. Pharmacotherapy 1997; 17: 31S-38S.

30. Everson RB, Schreinemachers DM, Devlin RB, Koren HS. Host determinants of cellular and biochemical constituents of bronchoalveolar lavage fluids: implications for design of epidemiologic studies. Am J Respir Crit Care Med 1994; 149: 899-904.

31. Nicholas TE, Barr HA. The release of surfactant in rat lung by brief periods of hyperventilation. Respir Physiol 1983; 52: 69-83. 